\title{
Contribution of language to the creation of corporate social capital
}

\author{
Krishna S. Dhir \\ Széchenyi István University \\ krishnadhir@yahoo.com
}

\begin{abstract}
With increased globalization of trade and business in a knowledge-based economy, and increasing diversification of the workforce, there is increasing pressure on multinational companies to report, and even measure, their social capital. This article explores the role of language in the creation of corporate social capital. The language used in a corporation is an asset, which creates value and corporate social capital in the use and exchange of ideas. Linguists have long attempted to assess the value of language as a commodity, but with little success. This article offers an approach to overcome this difficulty and to measure the value of language as an element of corporate social capital. To do so, it draws an analogy between the functions of language and functions of currency. The article goes on to suggest that multinational corporations should hold a portfolio of language skills, much as it does a portfolio of currencies.
\end{abstract}

Keywords: Social capital, Language; Policy, Value of language, Language portfolio, Utility of language 


\section{Introduction}

A number of factors contribute to the creation of corporate social capital. Language is one of these factors. Its contribution, and indeed that of all other contributing factors as well, is assessed subjectively, depending on the perceptions the management has of the specific relationship between these factors and the strategic environment within which the corporation exists and operates. The management of a corporation would do well to begin by identifying each of the contributing factors at the outset. This article focuses on the contribution of language as one of the factors in the creation of corporate social capital. To determine the contribution a language makes to corporate social capital it would help to know the value that language holds for the corporation concerned. This value depends on the strategic environment within which the corporation exists and operates. Just as the value of any asset depends on the specific relationship the owner of the asset has with that asset, so will different languages have different values for different corporations, depending on the managerial perceptions of the specific role the language plays in that corporation's strategic environment and context.

Corporations generally articulate their mission by describing the relationship they seek to establish with the society within which they exist. With the increased globalization of business and economy, organizations bring together people with different cultural orientations, who do not all speak the same language, but work toward a common organizational mission. From the languages available to them, corporations choose the particular working language which offers the most economically efficient way of creating and managing knowledge within the context of the strategic environment in which they exist and operate. By using their chosen language, the corporate community creates social capital. Putnam (1996: pp. 66) describes social capital to be about people in a community acting together to achieve shared objectives. He states that there are three prerequisites that facilitate the creation of social capital: (i) community norms - the common values and rules that people in the community share. These encourage, or even constrain, people to work for the common good, even foregoing what might be best for them collectively or even individually in the short term; (ii) the networks - the groupings and cross-groupings of people and organizations which facilitate people working together; and (iii) trust, which enables the members of the community to share information and responsibilities more readily as they work towards common objectives (Putnam, 1996). Although Putnam does not explicitly mention the role of language in the creation of social capital, it is obvious that networking would require commonality in language use; that is, those in the network communicate and interact through a language known to the parties involved. 
While social capital pertains to shared objectives, it benefits individuals, too, by creating buman capital which enables individuals to acquire skills, competencies and qualifications, within a family, organization or community. Putnam is not alone in offering a description for social capital. A number of scholars have offered a variety of descriptions for social capital. Coleman (1994) has defined social capital as those expectations for action within a collectivity that affect the economic goals and goalseeking behavior of its members, even if these expectations are not oriented toward the economic sphere. The University of Michigan's Institute for Social Research describes social capital as follows: "Social capital ... is more than simply having social connections and networks. Social capital is exhibited in individuals who have a well-developed sense of mutual trust and 'give-and-take' or 'reciprocity' in their social networks. Moreover, it is exhibited in individuals who are actively engaged in civic and political life. This trust, reciprocity, and civic and political engagement then enrich the communities where these individuals reside" (Institute for Social Research, 2018). In Basel, Switzerland, the Basel Institute of Commons and Economics offers to measure social capital of organizations. This is a challenging task. They recognize that despite the distinction between social capital and financial capital and human capital, there is still some confusion about its meaning. They recognize that social capital "cuts across with a couple of societal, economical, and political issues" such as social networks, social entrepreneurship, social development, public goods, civil society, social cohesion, voluntarism, philanthropy, and solidarity (Dill, 2015).

Even though the concept of social capital has been actively discussed since the 1990s, defining the concept continues to be a challenge to this day. By 2004, a variety of perspectives and definitions for the concept of social capital had already been offered by various scholars (including Belliveau, O'Reilly and Wade, 1996; Bourdieu, 1986; Bourdieu and Wacquant, 1992; Boxman, De Graal and Flap, 1991; Brehm and Rahn, 1997; Burt, 2001; Coleman, 1994; Fukuyama, 1997; Knoke, 1999; Lin, 1999; Nahapiet and Ghoshal, 1998; Portes, 1998; Putnam, 1995; Smith and Kulynych, 2002; Thomas, 1996; and Woolcock, 1998). Claridge discussed many of these definitions in his thesis (Claridge, 2004). The effort to get a better grasp on the concept of social capital has continued throughout the past decade (Adam, 2011; Curley, 2010; Foley and O'Connor, 2013; Fulkerson and Thompson, 2008; Hays, 2015; Westlund and Adam, 2010). Social capital may well be difficult to define because scholars cannot account for the vast range of elements contributing to it in a brief description. Clark (2006) states, "Whereas numerous commentators have addressed questions of aetiology, cultivation, distribution, and effects of social capital, there is as yet no satisfactory explanation 
of what it is as such". He defines social capital as follows: "Social capital is the productive value of relationships between people. It consists in the networks of relationship available to individuals and groups, such as families, friendships, work, clubs, religion, neighbourhood, political affiliations, and ethnicity" (Clark, 2006). He goes on to state, "It also consists in the environmental and cultural conditions in which those networks operate, such as the strength of identification between a network and its members, the trust and/or sympathy that exist among them, and the norms of reciprocity within a network that may be inferred from the attitudes and behavior of its members" (Clark, 2006).

What is evident in the various definitions of social capital is that it is created through relationships among individuals, either as members of the institutions they represent or in their own capacity. The language of communication is an essential asset in the exchange of ideas, sentiments, information, narratives, and messages that create, maintain, and sustain relationships. Yet, surprisingly, most definitions fail to identify language as a significant factor in promoting social capital. Fortunately, recent scholars have begun to acknowledge it (GallagherBrett, Doughty and McGuinesss, 2014; Joksimović et al, 2018; Khodadady and Ashrafborji, 2016; Neely, Hinds and Cramton, 2012). Before Ciba-Geigy and Sandoz merged in 1996 to create Novartis, there were three pharmaceutical multinational corporations headquartered in Basle, Switzerland. These were CibaGeigy, Sandoz, and Hoffmann-La Roche. Each had different working languages: English, French, and German, respectively. This difference in their respective working languages suggested that these languages contributed differently to the creation of social capital for these corporations. Indeed, the focus of this article is on the importance of language in the creation of corporate social capital, not on social capital itself. Different value may be accrued to different corporations through the same language. Different languages may contribute differently to the social capital created for the respective corporation. Dhir $(2004,2005)$ has described elsewhere an approach to capture the subjective process for assessing the value of language. This article emphasizes that by assessing the value of a language the contribution of that language to the creation of corporate social capital can be captured. 


\section{Trends shaping the creation of social capital}

Dhir $(2004,2005)$ has described three major trends that shape corporations today. These are the trends in the (i) knowledge economy, (ii) globalization of business and economy, and (iii) diversity of the workforce. These three trends are also shaping the processes by which a corporation's social capital is created. Also see Grin et al. (2010), Esperança (2008), and Garcia Delgado et alii (2012).

\subsection{The evolution of the knowledge economy}

Dhir (2004) noted that traditional theory "views an organization as a system that processes information and solves problems through decision-making. It seeks to improve the efficiency with which information is processed within the context of decision making in an uncertain environment". The literature on the process of creating and managing knowledge demonstrates that organizations create and manage both information and knowledge (Amidon, 1997; Foss and Pedersen, 2004; Kolodny et alii, 1996; Nonaka 1994; Scarbrough 1996). The role of knowledge creation in a multinational corporations has continued to attract investigations (Nonaka and von Krogh, 2009; Nonaka, von Krogh and Voelpel, 2006; Stacey, 2001). It is generally understood that knowledge is transferred through language although not all languages are equally efficient at doing so. This knowledge is then aligned with local or regional culture, thus establishing the conditions for creating social capital.

Dhir has emphasized the role of language in knowledge creation. He contrasted information-driven organizations with knowledge-driven organizations in the following terms. Information-based organizations "focus on knowing facts acquired through information that is often obtained by formal education. Information is independent of the individual creator. Its transfer is quick and mass oriented" (Dhir, 2004). The cost structures in information-driven organizations are distinct from those in knowledge-driven organizations. As stated by Dhir (2004), "Informationdriven organizations bundle information into standardised packages for a mass of customers. The major costs of communication are developmental. The cost of increasing volume is minimal." In contrast, knowledge-driven organizations usually not only make the knowledge available but enable others to use it. They transfer knowledge. The party acquiring the knowledge might undergo training, reflect on the knowledge acquired, engage in repetitive exercises, make mistakes, and learn through practice. The transfer of knowledge requires an efficient language and generally takes time. It is usually accomplished on an individual, person-to-person basis. The costs of delivering knowledge-based services are usually related to the 
transfer of knowledge and the capacity to use that knowledge. This may include the cost of language translation. In contrast to the cost structures of information-based organizations, the main cost for knowledge-based organizations is at the stage of delivering the service. Sveiby explains that these costs increase with volume (Sveiby 1997: 24-50). Complex organizations have elements of both information-driven organizations and knowledge-driven organizations. Demands for new corporate competencies are motivated by five factors: new stakeholders, expectations, technologies, time horizons, and competition (Dhir and Harris, 2001). New stakeholders call for a focus on important corporate competencies, and expect corporations to develop processes that add value. Dhir and Harris explain that "this requires that corporations focus less on activities designed to convert events into information (e.g., collecting, classifying and summarizing activities) and focus more on activities designed to transform information into knowledge (e.g., analyzing, interpreting, and evaluating activities that drive the decision making process)" (Dhir and Harris, 2001). New technologies are emerging at a rapid rate. They are disruptive in that they make dramatic improvements to methods and efficiency through innovation, and they create values in society that were difficult to foresee even just one decade ago. The rate at which business environments change in our times has converted the long-term of the past into the short-term of today. The pace of change has profound implications for continuing education, professional development, and entrepreneurship. Corporations competing in knowledge-based markets have to be agile and responsive at an ever increasing rate of adaptation. All the factors and issues described here suggest new competitors and new ways of competing. New stakeholders, new technologies, new time horizons, and the rapidly changing profile of the market call for competitive strategies that invite new players who are more agile and better able to compete, in the market. All the five factors mentioned above have major implications for communication, both within organizations, between organizations, and beyond organizations, with social entities or external stakeholders. Language that facilitates communication is important to each of the five factors described above.

\subsection{Globalization of business}

One noticeable response to the increasing demands for intellectual capacity and the advent of technology-based entrepreneurship is that organizations, multinational corporations in particular, are bringing together individuals who have been nurtured in different cultural and political milieus, under different degrees of industrial and economic development, and educated in different socio-cultural conditions in different parts of the globe. They often have different 
language competencies. Yet, together, they work towards a common organizational mission. This trend moves the corporation toward the globalization not only of the markets but of the workforce and personnel as well. The languages of employees have a profound impact on the ability of corporations to compete in a global marketplace. However, the strategic management literature does not offer much discussion of the role of language in the positioning of the multinational companies for effective competition. Also, the strategic role of language from the perspective of corporate policy is generally ignored in the broader communications literature (Dhir and Gòkè-Paríolá, 2002). Recently, scholars have suggested that the language in which business transactions occur should be addressed as a strategic issue, especially in multinational corporations that operate in the trans-national, global markets. Language in the context of strategic management has attracted considerable interest (Barner-Rasmussen et al, 2014; Brannen and Doz, 2012; Brannen, Piekkari and Tietze, 2014; Dhir, 2005; Dhir and Gòkè-Paríolá, 2002; Dhir and Savage, 2002; Harzing and Pudelko, 2013; Marschan, Welch and Welch 1997; Peltokorpi and Vaara, 2012; Piekkari and Tietze, 2011; Piekkari and Zander, 2005).

Corporations often adopt a single language as their official working language. They do this to promote efficiency of communication and operation. Nevertheless, Ghoshal and Bartlett (1995) have observed that "multinational corporations favor the development of a strong sense of common purpose, managed through soft control processes that operate through informal communication channels, rather than formal means" (Dhir, 2004). As stated by Dhir,"personal relationships within an organization define the feasibility and the effectiveness of communication, collaborative learning, and knowledge creation, with direct implications for the corporation's competitive advantage in its strategic environment... Yet, the strategic management literature rarely discusses the impact of language on multinational operations ... beyond acknowledging its importance, even when otherwise focused on the importance of local considerations in effective management of international business" (Dhir, 2004). A common language deployed throughout a multinational corporation may well minimize "uncertainty and loss of information", and integrate "diverse members of a multinational organization into a single, cohesive and effective corporate body" (Dhir, 2005). However, Marschan-Piekkari, Welch and Welch (1999), and Welch, Welch, and Marschan-Piekkari (2001), have suggested that a common corporate language might very well hinder or even alter the flow of information, and influence effective transfer of knowledge. Dhir and Gòkè-Paríolá (2002) have argued that not allowing a diversity of languages in an organization through 
imposed standardization may in fact deprive the organization of critical resources. Organizational members bring diverse perspectives from different cultures that may offer unique values and opportunities to the company. A variety of languages may bring a critical understanding of different cultures that can give a multinational corporation a strategic and competitive advantage. Dhir and GòkèParíolá (2002) have suggested that multinational companies should develop language policies that reflect the strategic environment within which they exist. Dhir (2005) has noted that with "rare exceptions (Dhir and Gòkè-Paríolá, 2002; Marschan, Welch and Welch, 1997) the need for corporate language policies has not been adequately recognized in either the strategic management literature or in the communications literature."

\subsection{Workforce diversity}

Over the past three decades, the impact of workforce diversity on corporate functioning has been studied with considerable interest (Alesina and Ferrara, 2005; Cox 1993; Garnero and Rycx, 2013; Harrison and Klein, 2007; Jackson and Ruderman, 1995; Kurtulus, 2011; Parrota, Pozzoli and Pytlikova, 2012; Roberge and van Dick, 2010; Saxena, 2013). Does cultural diversity enhance work group functioning, or does it detract from their efficiency? Some literature recommends that managers should increase workforce diversity to enhance work group effectiveness, in both domestic and global organizations. Yet, empirical research in support of these recommendations is limited. Saxena (2013) reports that "employing diversified workforce is a necessity for every organization but to manage such diversified workforce is also a big challenge for management." In a study in Denmark, Parrotta, Pozzoli and Pytlikova (2012) found that "labor diversity in education significantly enhances a firm's value added. Conversely, diversity in ethnicity and demographics induces negative effects on firm productivity. Therefore, the negative effects, which are derived from the communication and integration costs associated with a more culturally and demographically diverse workforce, seem to outweigh the positive effects of creativity and knowledge spillovers." Garnero and Rycx (2013) estimated "the impact of workforce diversity on productivity, wages and productivity-wage gaps (i.e. profits) using detailed Belgian linked employer-employee panel data. They found that educational (age) diversity is beneficial (harmful) for firm productivity and wages. The consequences of gender diversity are found to depend on the technological/knowledge environment of firms. While gender diversity generates significant gains in high-tech/ knowledge intensive sectors, the opposite result is obtained in more traditional industries. Overall, findings do not point to 
sizeable productivity-wage gaps except for age diversity." Understanding how workforce diversity impacts an organization remains a difficulty. For example, studies on race and gender have demonstrated both positive and negative impacts on work group functioning (Phillips and O'Reilly 1998). In another instance, Pelled (1996) makes one set of predictions about how group work members are affected by racial diversity, and another about how they are affected by functional background diversity based on the visibility of race and job-relatedness ... Different researchers hypothesize different models for the impact of diversity on work group effectiveness (Dhir, 2005). The factors that one researcher expects to impact work group effectiveness negatively are thought to affect it positively by another. For instance, Pelled (1996) expected that racial diversity would impact work group effectiveness negatively. However, Cox, Lobel, and McLeod (1991) expected racial diversity to have a positive outcome. It is noteworthy that while workforce diversity studies account for the impact of demographic variables including age, race, ethnicity, gender, social class, religion, nationality, sexual orientation, and physical disability, they do not generally address language as a personal characteristic. While most personal characteristics of employees are more or less fixed and cannot be changed by corporate managers, language can be learned.

As stated by Clark (2006), "if there is a substantial phenomenon called social capital, then one of its manifest forms is language." Language is at the heart of knowledge creation, storage, distribution and transfer, and communication within a workforce, or across globalized markets. Created through relationships, social capital requires interactions. Clark (2006) said that "human relations are incomprehensible without language". He also stated that "one obstacle impeding the development of a social capital ontology has been the question of measurement". The value of a multinational corporation's social capital is determined by the contribution various elements of the capital make to it. Here we describe how the value of language as an element of social capital can be determined.

\section{Assessing the value of language}

The approach to the valuation of language described here is inspired by the concept of the valuation of currency. In economic communities, currencies are used to:

i) Account for value

ii) Store value

iii) Exchange value 
To account for value, currency is used to denominate financial instruments and invoice trade. Currency is used as an investment asset that can be stored over time, to be retrieved at a later date. It is also used as a medium of exchange for an asset that is deemed to be of the same value. Different currencies may be used for accounting, storing, and exchanging amounts of the same value. An analogy can be drawn between currency and language. Different languages can be used to convey the same message. Languages, too, performs the three functions of accounting, storing, and exchanging, in the context of knowledge, information, and culture. Culture, in turn, is based on knowledge and information. A language is used to:

a) Account for knowledge and information

b) Store knowledge and information

c) Exchange knowledge and information

It is clear that in different markets - or economic communities - around the globe, different currencies are used to account for, store or exchange value. These currencies are also converted from one to another. Similarly, in different social or corporate communities, different languages are used to account for, store or exchange knowledge or information - or culture - and languages can be translated from one to another. Dhir (2005) goes farther with the analogy between currency and language. He observes that the "value of a currency to an organization operating in an economic environment may be affected by such considerations as the demographic range in which the currency is used, the degree of investment made in that currency by the economic community, the general demand for the currency, and so on. Similarly the value of a language to an organization may be affected by the degree to which the language is used in the demographic community defining the organization's strategic environment, the investment in the language relative to other available languages, the demand for the language as a commodity within the organization's strategic community, and so on. Just as different prevailing economic trends have implications for strategies devised for the management of currencies held by a company, different social trends have implications for the management of a corporation's language assets" (Dhir, 2005). Dhir and Savage (2002) used these analogies to develop an approach to the assessment of value of languages, within the context of an organization's strategic environment.

Well over two decades ago, Coulmas had already observed that language was an element of the economic process in which organizations, and corporations, functioned. However, at that time, Coulmas also noted that it was difficult to assign value to language because of the difficulty in "weighing of the factors" contributing to its value, due to "a deficit in theoretical and empirical 
research..." (Coulmas, 1992: 88-89). Soon after, Grin (1996) called for a study of the economics of language, in terms of such linguistic considerations in which economic variables also play a part. As stated by Dhir (2005), "Linguistic variables of language may include ... percentage of a population that speak a particular language, domains or situations of use, attitudes towards the use of a language (e.g., whether the knowledge of a particular language gives the speaker high or low social status), maintenance and spread of the language, formal and informal patterns of use in the language, knowledge creativity in the language, etc. Economic variables in relation to language include costs to the community of learning a language, enhancement in the level of income derived using a language, unemployment due to lack of language ability, etc."

Coulmas (1991) refers to the utility of a language, noting that the value of the language may vary with its suitability for performing specific tasks. For instance, some languages may be more effective than others for communication in different places, to different audiences, and at different times. Coulmas also notes that in international transactions and global markets, different languages offer different values in exchange, determined by the demand for the language in the specific context."Both the utility value and the exchange value of language can vary from context to context and markets to markets" (Dhir, 2005). Fortunately, advances in applied psychology, model building, rapid computer-based data handling and processing, graphic displays, et cetera, have now removed the deficits in theoretical and empirical research lamented by Coulmas. It has now become possible to assess the subjective processes underlying the valuation of languages, within the strategic context in which corporations operate.

The economic considerations involved in the decision-making process can be analyzed to address the issue of a multinational corporation choosing its working language. Relying heavily on the clues provided by Coulmas (1992) in regard to the utility value of language, Dhir and Savage (2001) developed an approach to assess the value of a language, within the context of a firm's strategic environment. Of the various theories of decision making available in the decision analysis literature, they settled on judgment analysis based on Social Judgment Theory (Cooksey, 1996). They preferred this theoretical framework to others because it does not prescribe how rational decisions should be made. Their objective was to account for the subjective valuation process from the perspective of developing a corporate policy for assigning relative value, not to define a prescriptive approach to the valuation of a language. Neither did they wish to compare observed decision behavior with a rational prescription. They merely wanted to describe the process of the assessment being deployed by individuals (Cooksey, 1996: pp. 
26-54). The approach they used is a process of individual judgment, from which judgment and decision aids can be developed.

\subsection{A Case Study}

For illustrative purposes, consider the following case. A consultant is hired by an aspiring multinational firm, presently operating in Romania. The company has decided to expand into Europe, including markets in England, Germany and France. While German and French are recognized minority languages in Romania, English is not. The managers of this growing firm feel they need to choose additional language, or languages, to (i) serve as a medium of communication, so that the firm may engage in effective inter-subsidiary communication; (ii) acquire a local identity in markets where Romanian is not a familiar language; and (iii) to create human and intellectual capital in the local markets. The consultant is asked to assist the policy makers of the multinational company in developing a language policy that would inform what language or languages should be adopted by the company.

The consultant sets out on the task, asking at the outset what the purpose of the policy is, and is told that the goal is to maximize the potential for creating corporate social capital. The consultant decides to assess the value of the language in terms of its potential to create corporate social capital, within the context of the company's strategic environment. The consultant then inquires what linguistic factors enhance the process of creating corporate social capital. The following factors are identified as contributing to the value of language, within the context of the company's strategic environment:

a) Demographic Range - the degree to which the language is used in the demographic community relative to other languages available within the multinational company's strategic environment (both external and internal).

b) Total Investment - the degree to which the demographic community collectively invests in (that is, learns or prefers) the language relative to other languages available in the organization's internal environment.

c) Demand - the degree to which the language is demanded as a commodity within the demographic community relative to other languages available within the multinational company's strategic environment (both external and internal).

d) Knowledge Creativity - the degree to which the demographic community creates knowledge in the language relative to other languages available 
within the multinational company's strategic environment (both external and internal).

e) Functional Potential - the degree to which the language can be developed as the multinational business organization's economic means of production within the time frame of its strategic plan relative to other languages available.

To determine the relative importance of these factors, the consultant presents the corporate policy makers a set of, say, twenty hypothetical profiles of languages. In these profiles, each of the five factors, a) through e), are presented with random values on a scale from 1 to 10 , where 1 represents a factor to be present at an extremely low level, and 10 represents the factor to be present at an extremely high level. The consultant ensures that the twenty profiles are designed with orthogonal values assigned to the five factors (that is, they are not intercorrelated).

The consultant now asks the corporate policy makers to rate each of the twenty profiles for their respective usefulness, or utility, to the company on a scale from 1 to 10 , where a rating of 1 indicates that the language represented by the profile has an extremely low utility for the company, and a rating of 10 indicates that the language has an extremely high utility for the company. When all the profiles have been rated, and the raters are satisfied with the ratings they have assigned to the respective profiles, the consultant performs nonlinear regression analyses for each policy maker. The consultant uses a second order model for the regression to capture the weights each policy maker assigns to the factors and the nonlinearity resulting from the level at which each of the five factors are present in the various profiles. The regression analyses also yield the cognitive consistencies of each of the policy makers in exercise of their respective judgments, in terms of the multiple correlation coefficient. For mathematical details regarding these analyses, see Cooksey (1996: 178-180). In this way, the policy of each policy maker can be obtained in terms of the relative weight assigned to each factor considered and the functional relationship between the factor and the overall rating of utility derived from various language profiles. These profiles can then be applied to the other languages being considered and the ones that best suit the policy makers can be chosen. For further elaboration, detailed description, and discussion of the method for determining the value of languages described above, see Dhir and Savage (2002) and Dhir (2005). An example of the process of determining the value of a language within a firm's strategic environment and formulating a corporate policy from this valuation is presented in Dhir and Savage (2002). 


\subsection{A portfolio of languages}

Assessing the value of languages within the strategic context in which a multinational corporation operates opens up interesting language possibilities for the management of multinational corporations. Valuations of currencies help multinational corporations to determine the optimal portfolio. Similarly, valuations of languages, within the context of the corporation's strategic environment, help the corporation to determine the portfolio of languages. This suggests the need for plurality of language skills among the corporate managers.

The implication is that multinational corporations need to recruit managers who are multilingual and carefully place these language skills at key positions for maximum impact and efficiency in the creation of corporate social capital. The distribution of language competencies in the various hierarchical levels of a corporation would be determined by the specific organizational design, which in turn may be determined by the specific goals and the overall mission of the corporation.

\section{Concluding remarks}

This article has discussed the importance of languages in creating corporate social capital in multinational corporations. Relationships that are essential for creating corporate social capital depend on the languages deployed within the corporation. The role of language is becoming increasingly important in the emergence of the knowledge-based economy, the globalization of business, and the increasing diversification of the workforce. With these trends leading to complex internal and external competitive environments, multinational corporations are experiencing increasing pressure to understand and design the processes that create their respective social capital. They urgently need to assess the value of their social capital but this valuation itself is challenging.

The languages used in a corporation are assets that create value and corporate social capital through their use and the exchange of ideas. As mentioned above, a number of factors contribute to the creation of corporate social capital. Language is one of them. Linguists have long attempted to assess the value of language as a commodity, but with limited success. This article suggests that the existing studies on the assessment of the value of language be extended to the contribution language makes to the creation of corporate social capital.

It is important to recognize languages as elements of corporate social capital, within the strategic environment in which corporations operate. The three major trends shaping modern corporations all focus on the increasing role and 
importance of language in the creation of corporate social capital. The emerging trends in the knowledge economy go beyond information processing, the globalization of business and economy, and the diversification of the workforce, and emphasize the importance of taking language into account as a strategic factor creation of social capital.

To bring home the concept of value of language to a corporation, this article draws an analogy between currency and language. Currency and language have similar functions in that they account for, store, and exchange value. Money gets transacted through currencies. Messages get transmitted through languages. And they are often managed in similar ways as well. One currency can be converted into another. Languages get translated. Ecuador, El Salvador, and Zimbabwe, adopted the US Dollar though currency substitution. India has adopted English as its working language.

Just as multinational corporations often maintain a portfolio of currencies, they could also develop and maintain a portfolio of languages for maximizing the creation of their corporate social capital. Exactly how specific language competencies are distributed throughout the corporate hierarchy would depend on the corporate design and how these competencies can be most effectively used to execute its goals and fulfill the corporate mission.

This article has emphasized language as a factor in the creation of corporate social capital. As stated, language is one of various factors that contribute to the creation of social capital. It is important that the corporation begin by identifying all of the contributing factors at the outset and determining how they are related to the strategic environment within which the corporation exists and operates. The approach applied to language could conceivably be applied to other factors as well.

\section{References}

AdAm, Frane (2011). "Regional innovation performance in light of social-capital research and application". Social Science Information, 50 (3-4):414-428.

Alesina, Alberto and La Ferrara, Eliana (2005). "Ethnic diversity and economic performance". Journal of Economic Literature, 43 (3)ः 762-800.

Amidon, D. M. (1997). Innovation Strategy for the Knowledge Economy: The Ken Awakening, London: Butterworth-Heinemann.

Barner-Rasmussen, Wilhelm; Ehrnrooth, Mats; Koveshnikov, Alexei and Mäkelä, Kristina (2014). "Cultural and language skills as resources for boundary spanning within MNC". Journal of International Business Studies, $45(7): 886-905$. 
Belliveau, M.A.; O’Reilly, Charles A. and Wade, James (1996)."Social capital at the top: Effects of social similarity and status on CEO compenzation". Academy of Management Journal, 39 (6): 1568-1593.

Bourdieu, P. (1986). "The forms of capital", in John G. Richardson (Ed.) (1986). Handbook of theory and research for sociology of education. New York: Greenwood Press.

Bourdieu, P. and Wacquant, L.P.D. (1992). An invitation to reflexive sociology. Chicago: University of Chicago Press.

Boxman, Ed A.W.; De Grant, Paul M. and Flap, Hendrik D. (1991). Impact of social and human capital on the income attainment of Dutch managers". Social Networks, 13 (1): 51-73.

Brannen, Mary Y. and Doz, Yves L. (2012). “The language of strategic agility: Trapped in your jargon or lost in translation?" California Management Review, 54 (3): 77-97.

Brannen, Mary Y; Piekrari, Rebecca and Tietze, Susanne (2014). "The multifaceted role of language in international business: Unpacking the forms, functions and features of a critical challenge to MNC theory and performance". Journal of International Business Studies, 45 (5): 495-507.

Brenm, John and RahN, Wendy. (1997)."Individual-level evidence for the causes and consequences of social capital”. American Journal of Political Science, 41 (3): 999-1023.

Burt, Ronald S. (2001). "Structural holes versus network closure as social capital”, in Nan Lin, Karen S. Cook and R.S. Burt (Eds.) (2001), Social capital: Theory and research. Hawthorne, NY: Aldine de Gruyter.

Claridge, T. (2004). "Social capital and natural resource management: An important role for social capital?”Unpublished Thesis. Brisbane, Australia: University of Queensland.

Clark, Tom (2006)."Language of social capital". Applied Semiotics - Semiotique Appliquee, 8 (18): 29-41.

Coleman, James S. (1994). Foundation of social theory. Cambridge: Belnap Press of Harvard University Press.

Cooksey, R.W. (1996). Judgement analysis: Theory, methods, and applications. San Diego: Academic Press.

Coulmas, Florian (1991). "The language trade in the Asian Pacific". Journal of Asian Pacific Communication, 2 (1): 1-27.

Coulmas, Florian (1992), Language and economics. Oxford, UK: Blackwell Publishers. 
Cox, T.H., Jr. (1993). Cultural diversity in organizations: Theory, research, and practice. San Francisco: Berrett-Koehler.

Cox, Taylor H.; Lobel, Sharon A. and McLeod, Poppy L+ (1991), "Effects of ethnic group cultural differences on cooperative and competitive behavior on a group task". Academy of Management Journal, 34 (4): 827-847.

Curley, Alexandra M. (2010). "Relocating the poor: Social capital and neighbourhood resources". Journal of Urban Affairs, 32 (1):79-103.

Dhir, Krishna S. (2004). "Language as a corporate asset”, in Sandra M. Oliver (Ed.) (2004), A handbook of corporate communication and strategic public relations: Pure and applied. London: Routledge.

Dhir, Krishna S. (2005). "The value of language: Concept, perspectives, and policies". Corporate Communications: An International Journal, 10 (4): 358 382.

Dhir, Krishna S. and Gòkè-PAríolá, Abíódún (2002). "The case for language policies in multinational corporations". Corporate Communications: An International Journal, 7 (4): 241-251.

Dhir, Krishna S. and Harris, Jean E. (2001). "The emerging paradigm for information and knowledge creation in academic organizations". International Journal of Management Literature, 1 (2, 3 \& 4): 305-315.

Dhir, Krishna S. and Savage, Theresa (2002). "The value of a working language". International Journal of the Sociology of Language, 158: 1-35.

Dill, Alexander (2015). What is social capital 2015 - a review. Basel, Switzerland: Basel Institute of Commons and Economics.

Esperança, JoséPaulo (2008). An Eclectic Approach to Language Valuation. Lisbon: Instituto Camões.

Foley, Dennis and O'Connor, Allan John (2013). "Social capital and the networking practices of indigenous entrepreneurs". Journal of Small Business Management, 51 (2): 276-296.

Foss, Nicolai Juul and Pedersen, Torben (2004). "Organizing knowledge processes in the multinational corporation: An introduction". Journal of International Business Studies, 35 (5):340-349.

Funuyama, Francis (1995). Trust: The social virtues and the creation of prosperity. London: Hamish Hamilton.

Funurama, F. (1997), "Social Capital and the Modern Capitalist Economy: Creating a High Trust Workplace”, Stern Business Magazine, Vol. 4 No. 1.

Funurama, F. (1997), "Social Capital and the Modern Capitalist Economy: Creating a High Trust Workplace", Stern Business Magazine, Vol. 4 No. 1. 
Funurama, F. (1997), "Social Capital and the Modern Capitalist Economy: Creating a High Trust Workplace”, Stern Business Magazine, Vol. 4 No. 1.

Funuyama, Francis (1997). "Social capital and the modern capitalist economy: Creating a high trust workplace". Stern Business Magazine, 4 (1).

Fulkerson, Gregory M. and Thompson, Gretchen H. (2008). "The evolution of a contested concept: A meta-analysis of social capital definitions and trends (1988 - 2006)". Sociological Inquiry, 78 (4): 536-557.

Garcia Delgardo, José Luis; Alonso, José Antonio and Jiménez, Juan Carlos (2012). El valor económico del Español. Madrid: Fundación Telefónica.

Gallagher-Brett, Angela; Doughty, Hannah and McGuinness, Heather (2014). "Social capital and modern language initiatives in times of policy uncertainty". Scottish Languages Review, 27 (Spring/Summer): 39-52.

Garnero, Andrea and Rycx, François (2013). The heterogenous effects of workforce diversity on productivity, wages and profits. Bonn: Institute for the Study of Labor (IZA), Discussion Paper 7350.

Ghoshal, Sumantra and Bartlett, Christopher A. (1995). "Changing the role of top management: Beyond structure to process". Harvard Business Review, $73(2) \div 86-96$.

Grin, François (1996). "The economics of language: survey, assessment, and prospects". International Journal of the Sociology of Language, 121:17-44.

Grin, François; Sfreddo, Claudio and Valliancourt, François (Eds*) (2010). The economics of the multilingual workplace. New York: Routledge.

Harrison, Davis A. and Klein, Katherine J. (2007). "What's the difference? Diversity, constructs as separation, variety or disparity in organizations". Academy of Management Review, 32 (4): 1199-1228.

Harzing, Anne-Wil and Pudelko, Markus (2013). "Language competencies, policies and practices in multinational corporations: A comprehensive review and comparison of Anglophone, Asian, continental European and Nordic MNCs". Journal of World Business, 48 (1): 87-97.

Hays, Richard Allen (2015). "Neighborhood networks, social capital, and political participation: The relationships revisited". Journal of Urban Affairs, $37(2): 122-143$.

Institute for Social Research (2018). Social capital. Ann Arbor, Michigan: The Regents of the University of Michigan.

Jackson, S.E. and Ruderman, M.N. (1995) (Eds.). Diversity in Work Teams. Washington, DC: American Psychological Association.

Joksimović, Srećko; Dowell, Nia; Poquet, Oleksandra; Kovanović, Vitomir; Gašević, Dawson; Shane and Gaesser, Arthur C. (2018). 
"Exploring development of social capital in a CMOOC through language and discourse". The Internet and Higher Education, 36 (January); 54-64.

Khodadady, Ebrahim and Mozhgan, Ashrafborji (2016). "Social capitals and English language learning in an Iranian language institute". Journal of Language Teaching and Research, 7 (2): 328-339.

Knoke, D. (1999). "Organizational networks and corporate social capital", in S.M. Gавву (Ed.) (1999). Corporate social capital and liability. Boston: Kluwer Academic Publishers.

Kolodny, Harvey; Liu, Michel; Stryn, Bengt and Denis, Heline (1996)."New technology and the emerging organizational paradigm". Human Relations, 49 (12): 1457-1487.

Kurtulus, Fidan A. (2011)."What types of diversity benefit workers? Empirical evidence on the effects of co-worker dissimilarity on the performance of employees". Industrial Relations, 50 (4): 678-712.

Lin, Nan (1999). "Building a network theory of social capital". Connections, 22 $(1) \div 28-51$.

Marschan, Rebecca; Welch, Denice E. and Welch, Lawrence S. (1997). "Language: The forgotten factor in multinational management". European Management Journal, 15 (5):591-598.

Marschan-Piekkari, Rebecca; Welch, Denice and Welch, Lawrence (1999). "Adopting a common corporate language: IHRM implications". International Journal of Human Resources Management, 10 (3): 377-390.

Nahapiet, Janine and Ghoshal, Sumantra (1998). "Social capital, intellectual capital, and the organizational advantage". Academy of Management Review, $23(2): 242-266$.

Neely, Tsedal; Hinds, Pamela J. and Cramton, Catherine D. (2012).“The (un) hidden turmoil of language in global collaboration". Organizational Dynamics, 41 (3): 236-244.

NonAKa, Ikujiro (1994). "A dynamic theory of organizational knowledge creation". Organization Science, 5 (1): 14-37.

Nonaka, Ikujiro and von Krogh, Georg (2009). “Tacit knowledge and knowledge conversion controversy and advancement in organizational knowledge creation theory". Organization Science, 20 (3): 635-652.

Nonaka, Ikujiro; von Krogh, Georg and Voelpel, Sven (2006). "Organizational knowledge creation theory: Evolutionary paths and future advances”. Organizational Studies, 27 (8): 1179-120. 
Parrota, Pierpaolo; Pozzoli, Dario and Pytlikova, Mariola (2012). "Does labor diversity affect firm productivity?" Bonn: Institute for the Study of Labor (IZA), Discussion Paper 6973.

Pelled, Lisa Hope (1996). "Demographic diversity, conflict and work group outcomes: An intervening process theory”. Organization Science, 7 (6): 615 631.

Peltokorpi, V and VaAra, E. (2012). "Language policies and practices in wholly owned foreign subsidiaries: A recontextualization perspective". Journal of International Business Studies, 43 (9): 808-833.

Phillips, Katherine and O'Reilly, C.A. (1998). "Demography and diversity in organizations: A review of 40 years of research", in B. Staw and R. Sutton (Eds.) (1998). Research in Organizational Behavior. Greenwich* JAI Press.

Piekkari, Rebecca and Tietze, Susanne (2011). "A world of languages: Implication for international management research and practice". Journal of World Business, 46 (3): 267-269.

Piekkari, Rebecca and Zander, Lena (2005). "Language and communication in international management". International Studies of Management and Organization, 35 (1):3-9.

Portes, Alejandro (1998). "Social capitalः Its origins and applications in modern sociology". Annual Review of Sociology, 24 (August): 1-25.

Putnam, Robert D. (1995). "Bowling alone: America's declining social capital". Journal of Democracy, 6 (1): 65-78.

Roberge, Marie-Elène and van Dick, Rolf (2010). "Recognizing the benefits of diversity: When and how diversity increase group performance?" Human Resource Management Review, 20 (4): 295-308.

Saxena, Ankita (2013). "Workforce diversity: A key to improve productivity". Procedia Economics and Finance, 11:76-85.

Scarbrough, H. (Ed.) (1996). The Management of Expertise. London: MacMillan.

Smith, Stephen Samuel and Kulynych, Jessica (2002). "It may be social, but why is it capital? The social construction of social capital and the politics of language". Politics E Society, 30 (1): 149-186.

Stacey, R. (2001). Complex responsive processes in organizations. London: Routledge.

Sveiby, K.E. (1997). The new organizational wealth: Managing and measuring knowledge-based assets. San Francisco, CA: Berrett-Koehler Publishers, Inc.

Thомаs, Clive Y. (1996). "Capital markets, financial markets and social capital”. Social and Economic Studies, 45 (2/3): 1-23. 
Welch, Denice E.; Welch, Lawrence S. and Marschan-Piekkari, Rebecca (2001). "Persistent impact of language on global operations". Prometheus, 19 (3): 193-210.

Westlund, Hans and Adam, Frane (2010). "Social capital and economic performance: A meta-analysis of 65 studies". European Planning Studies, 18 (6): 893-919.

Woolcock, Michael (1998). "Social capital and economic development: Towards a theoretical synthesis and policy framework". Theory and Society, 27 (2): 151-208. 